\title{
Soriano-Colchero, Jose-Antonio.
}

Docente e Investigador pre doctoral. (FPU 15/05639). Universidad de Granada. Departamento de Dibujo. Grupo HUM 886 Dibujo y Proyecto.

\section{López-Vílchez, Inmaculada.}

Profesora Titular. Universidad de Granada. Departamento de Dibujo. Directora del Grupo HUM 886 Dibujo y Proyecto.

\section{La práctica artística como medio de representación de los modos de percibir la realidad espacial en el occidente contemporáneo. Un análisis teórico del proyecto plástico y visual No Vanishing Point ;)}

\section{The artistic practice as a way of representation of the modes of perceiving the spatial reality in the contemporary Western. A theoretical analysis of the artistic project entitled No Vanishing Point ;)}

TIPO DE TRABAJO: Comunicación.

PALABRAS CLAVE

Espacio, frontera, planicidad, percepción, arte.

KEY WORDS

Space, boundary, flatness, perception, art.

RESUMEN

El presente texto pretende desarrollar una aproximación teórica de la obra plástica y visual constituyente del proyecto artístico No Vanishing Point ;) realizado específicamente para su exposición en la Sala Ático del Palacio de los Condes de Gabia de Granada; a través de sus conceptos y claves principales. Proyecto que tiene como objetivo la reflexión acerca de la percepción y procesado de la información que recibimos durante nuestro día a día a través de las imágenes proyectadas desde los mass media como la televisión y las redes sociales principalmente; como metáfora de la percepción que los seres humanos tenemos actualmente de la realidad en la que habitamos. La sobreinformación que recibimos desde los medios nos impide la asimilación y digestión de la misma, dando lugar a un mensaje superficial que anula la capacidad de autocrítica, generando la planicidad del pensamiento, y con ello una percepción plana de la realidad. El concepto frontera se presenta como paradigma del no-espacio, como obstáculo insuperable hacia la búsqueda del espacio tridimensional con un punto de fuga. Como seres humanos occidentales pertenecemos a un espacio común interconectado a nivel global, totalmente virtual, cuyo único límite es la frontera en la que desaparecen los valores de consumismo compulsivo, así como la conceptualización superficial y la falta de profundidad argumental. Todo ello tiene como consecuencia el surgir de nuevas formas de representar el espacio, acordes al modo en que percibimos y conceptualizamos el mismo en nuestra contemporaneidad; continuando así con la serie de diferentes sistemas de representación espacial aplicados al arte que han tenido lugar a lo largo de la historia. Buscamos finalmente aportar una serie de conclusiones que den lugar a nuevas preguntas que permitan emprender un camino conductor hacia la reflexión crítica sobre la percepción contemporánea de nuestra realidad utilizando la práctica artística como medio 


\section{ABSTRACT}

This paper is based on the development of a theoretical analysis of the artworks which are part of the artistic project entitled No Vanishing Point ;), made particularly for its exhibition in the Sala Ático in the Palacio de Los Condes de Gabia in Granada; by means of its main concepts. The aim of the project is the reflexion on the perception of the information we receive in our daily life through the images from mass media such as the television or social media; as a metaphor of the perception of the reality in which human beings exist. The information overload we receive from the media does not let society assimilate the real information, giving rise to a kind of superficial message which destroys the aptitude for self-criticism, breeding a simplistic and consequently a flat perception of reality. The boundary as a concept is introduced as a paradigm of the non-space, like an unsurpassable obstacle through the searching of the three-dimensional space with a vanishing point. Western human beings belong to the common space worldwide connected, totally virtual, whose only limit is the boundary in which compulsive consumerism values disappear as well as superficial conceptualization and the lack of insightful thought. The consequence of this is the birth of new ways to represent space more similar to the mode in which we perceive and conceptualize it nowadays; continuing the sequence of different systems of spatial representation applied to art which have taken place along the history of art. Finally we try to provide some conclusions about the critical analysis of contemporary perception of reality using artistic practice as a medium.

\section{INTRODUCCIÓN}

No Vanishing Point ; ) es el título del proyecto artístico instalado en la Sala Ático del Palacio de los Condes de Gabia desde el pasado 02 de febrero de 2019 hasta el día 24 de marzo de 2019 en la ciudad de Granada. Dicho proyecto consta de una serie de pinturas sobre lienzo, una pieza de video arte y una pintura mural anamórfica.

Conceptualmente el proyecto gira en torno a la frontera en su connotación actual -véase (Querol, 2016, p. 215)-, como metáfora de la barrera que los medios de comunicación imponen en nuestro pensamiento a través de la influencia que generan sobre nosotros desde la sobreinformación, ejecutada desde el bombardeo diario de imágenes. Las imágenes producidas en este proyecto parten de videos tomados de los medios o cedidos por la Guardia Civil como materia prima, en los cuales se pueden visualizar saltos masivos de migrantes en las fronteras de Ceuta y Melilla. Pero la migración no es el tema principal. Los migrantes han sido sustituidos por mapas, haciendo referencia al plano y dando lugar a una nueva metáfora de la planicidad del pensamiento carente de reflexión crítica, inducida por los mensajes audiovisuales de los medios. La frontera al mismo tiempo se presenta como un no-espacio, un límite entre dos mundos paralelos y diferentes, separados por unos pocos metros. Como argumenta Zabell (2019) en el texto del catálogo:

"[...] ni hay profundidad ni la habrá; José Antonio se la ha sustraído para luego devolvérsela en un estado de mayor falsedad, la de la tramoya de teatro, donde las siluetas recortadas se apuntalan torpemente y se orientan hacia el público" (Dip. Granada, 2019. P. 10).

Conviene aclarar que no se trata de emprender una crítica hacia los demás ni hacia la sociedad, sino una invitación a la autorreflexión. Actualmente la imagen ejerce un papel fundamental en nuestra vida diaria, formando parte de nuestra educación y de nuestra forma de percibir la realidad. Es por ello que continuaremos el desarrollo del presente texto analizando su influencia en nuestro modo de percibirla.

\section{METODOLOGÍA}

Podemos anticipar que se trata de una metodología deductiva, ya que hemos partido de fuentes y bibliografías generales para poder concretar a través de las conclusiones finales. No obstante, la producción artística ha sido fundamental ya que se trata de un acercamiento teórico al proyecto artístico mencionado.

En primer lugar hemos estudiado las principales fuentes para poder localizarlas: libros -principalmente-, publicaciones científicas, catálogos, material audiovisual y gráfico, etc., sobre los diferentes conceptos principales que construyen nuestro trabajo. Dichos títulos podremos ir descubriéndolos a lo largo del texto. Cabe destacar entre la bibliografía empleada textos críticos acerca de la imagen y del arte. La recolección de datos a partir de estas fuentes establece un soporte fundamental a partir del cual hemos alcanzado la aprehensión de las ideas y conocimientos que forman los cimientos del presente proyecto.

A partir de la anterior recolección de datos hemos establecido el desarrollo del marco teórico conceptual a partir del cual hemos partido para la realización de nuestra propuesta de práctica artística personal como conclusión visual. De ahí la naturaleza crítico evaluativa de nuestra propuesta. La práctica en primera persona siempre lleva el estudio un paso más hacia delante. 
Soriano-Colchero, Jose-Antonio; López-Vílchez, Inmaculada.

La práctica artística como medio de representación de los modos de percibir la realidad espacial en el occidente contemporáneo. Un análisis teórico del proyecto plástico y visual No Vanishing Point ;).

IV Congreso INTERNACIONAL DE INVESTIGACIÓN EN ARTES VISUALES ANIAV 2019

IMAGEN [N] VISIBLE]

http://dx.doi.org/10.4995/ANIAV.2019.9223

\section{DESARROLLO}

Para tratar sobre la imagen partimos de estudios de J. T. Mitchell (2005), y sus consideraciones acerca de la relación entre la imagen y el observador. Así encontramos el doble sentido paradójico: en un origen, parece que las imágenes quieren algo de sus observadores, aunque somos conscientes de que esto no es así. Y por otra parte encontramos la consideración de la imagen como signo, cambiando la interpretación original, pues la historia del arte ha modificado nuestra interrelación con ellas.

En España encontramos los estudios de Jose Luís Brea (2010) que apuesta por que la imagen no contiene ningún mensaje concreto para el observador, sino que invita a la autorreflexión sobre nuestras experiencias y deseos; resultando imprescindible los contextos espacio-temporal y socio-cultural para esta interacción.

¿Pero qué hace posible la conexión entre el emisor y el receptor cuando hablamos de imágenes? La respuesta la encontramos en el soporte de la imagen y en el contexto, dando lugar al medio. Este medio como soporte ha ido cambiando a lo largo de la historia desde la fisicidad en un principio hasta la virtualidad actualmente con las nuevas tecnologías. Estos últimos medios hacen que las imágenes contemporáneas compartan muchas características con las imágenes mentales en cuanto a su carácter efímero y fluido. La imagen de los medios digitales tiene lugar en el presente y para el presente, sin intención de exhibirse como emisora de un concepto trascendental con el que interactuar con su observador, y sin intención de perdurar en el tiempo; diferenciándose de toda una tradición que la imagen-materia ha seguido anteriormente, e interactuando con el observador de una forma totalmente distinta.

"Aquí la imagen no mira al mundo -no se pretende pintura: fin del tiempo de la imagen como espejo o ventana-, pero tampoco a los ojos de quien la observa. [...] Aquí todo es pura actividad, digitación, expresión, fábrica, superficie y gestión de efectos" (Op. cit., p. 81).

\section{Nuestra realidad y la imagen}

A partir de la digitalización de la imagen se ha producido un fenómeno de difusión masiva de la misma, lo que hace que veamos más imágenes que nunca antes. Este hecho ha sido utilizado en beneficio propio por parte del sistema capitalista, que con sus campañas publicitarias y a través de la imagen, inserta en la sociedad los valores consumistas propios de nuestros tiempos. Por otra parte la aparición de las redes digitales también ha convertido al receptor en parte de esta trama, funcionando estos al mismo tiempo como emisores.

A consecuencia del ocularcentrismo ${ }^{1}$ (Op. cit., p. 90) ha tenido lugar una asimilación repetitiva y continua de los valores simbólicos de las imágenes por parte del sujeto, dando lugar a la construcción en su interior de una estructura a partir de la cual éste genera su realidad. "They change the way we think and see and dream. They refunction our memories and imaginations, bringing new criteria and new desires into the world"2 (Mitchell, 2005, p. 92). Esto implica que las imágenes tienen mucha facilidad para hacernos creer que lo que observamos en ellas sea considerado como verdadero, y en consecuencia, que lleguemos a considerar como hechos reales aquéllos que no lo son.

Por otra parte esta gran cantidad de imágenes a la que nos enfrentamos diariamente pueden hacernos dar por hecho que todo lo que sucede está fotografiado ${ }^{3}$, y que no seamos conscientes de que ocurren sucesos de los cuales no tenemos consciencia porque no interesa que éstos sean conocidos. En este sentido, Fontcuberta $(2016$, p. 26) apunta que aquello a lo que llamamos hipervisibilidad no sería más que hiperhipocresía.

Cabe hacer un tercer apunte acerca del peligro implicado por parte de la artificiosidad de la imagen contemporánea. Como argumenta Castro Flórez (2016, p. 12), en los mass - media "[...] el artificio adquiere carta de naturalidad", instaurando un extraño y engañoso estado de no - pensamiento. ¿Qué impide el pensamiento entonces? El artificio, el simulacro y la superficialidad, puesto que pensar ha sido siempre pesar. Así la masa queda inmune ante la imagen frenando su capacidad crítica, volviéndose apática.

Una posible alternativa a esta influencia que las imágenes ejercen sobre la sociedad es tener conocimiento de los estudios visuales ${ }^{4} \mathrm{y}$ lo que estos significan, pues pueden funcionar como herramienta defensiva a partir de la generación de preguntas sobre las mismas, que inciten a la reflexión crítica.

\footnotetext{
${ }^{1}$ José Luís Brea introduce el término “ocularcentrismo": soberanía de la vista por encima de los demás sentidos por parte de la sociedad en cuanto a la percepción de la realidad; tomado de la teoría del historiador y crítico cultural Martin E. Jay.

2 "Ellas cambian la manera en que pensamos y vemos y soñamos. Reconstruyen nuestras memorias e imaginaciones, trayendo nuevos criterios y deseos al mundo".

3 Véase el término de "postfotografía". (Fontcuberta, 2016, p.40).

${ }^{4}$ Asentados por Gottfried Boehm en Europa y Mitchell en EE.UU. (Mitchell, 2009)
} 
Soriano-Colchero, Jose-Antonio; López-Vílchez, Inmaculada.

La práctica artística como medio de representación de los modos de percibir la realidad espacial en el occidente contemporáneo. Un análisis teórico del proyecto plástico y visual No Vanishing Point ;).

IV Congreso INTERNACIONAL DE INVESTIGACIÓN EN ARTES VISUALES ANIAV 2019

IMAGEN [N] VISIBLE]

http://dx.doi.org/10.4995/ANIAV.2019.9223

\subsection{La imagen en el arte: apropiacionismo}

La propuesta sobre el arte contemporáneo por parte de los estudios visuales consiste en la democratización de la imagen artística. "Visual culture means an end to the distinction between artistic and non-artistic images, a dissolving of the history of art into a history of images. This might be called the "democratic" or "levelling" fallacy; [...]" (Mitchell, 2005, p. 346)5. El apropiacionismo como movimiento artístico se nutre de esta "democratización" de la imagen y del cambio en cuanto al valor de la misma. Dada la multiplicidad de la fotografía y de sus autores, el valor artístico de la imagen deja de fundamentarse en sus cualidades técnicas para pasar a su contenido conceptual. En nuestra contemporaneidad el apropiacionismo es valorado como otra posibilidad creativa más, evidenciando la relación existente entre lenguaje e imagen según Mitchell (2009). Así pues, la imagen encontrada en el archivo adquiere un nuevo significado tras su manipulación.

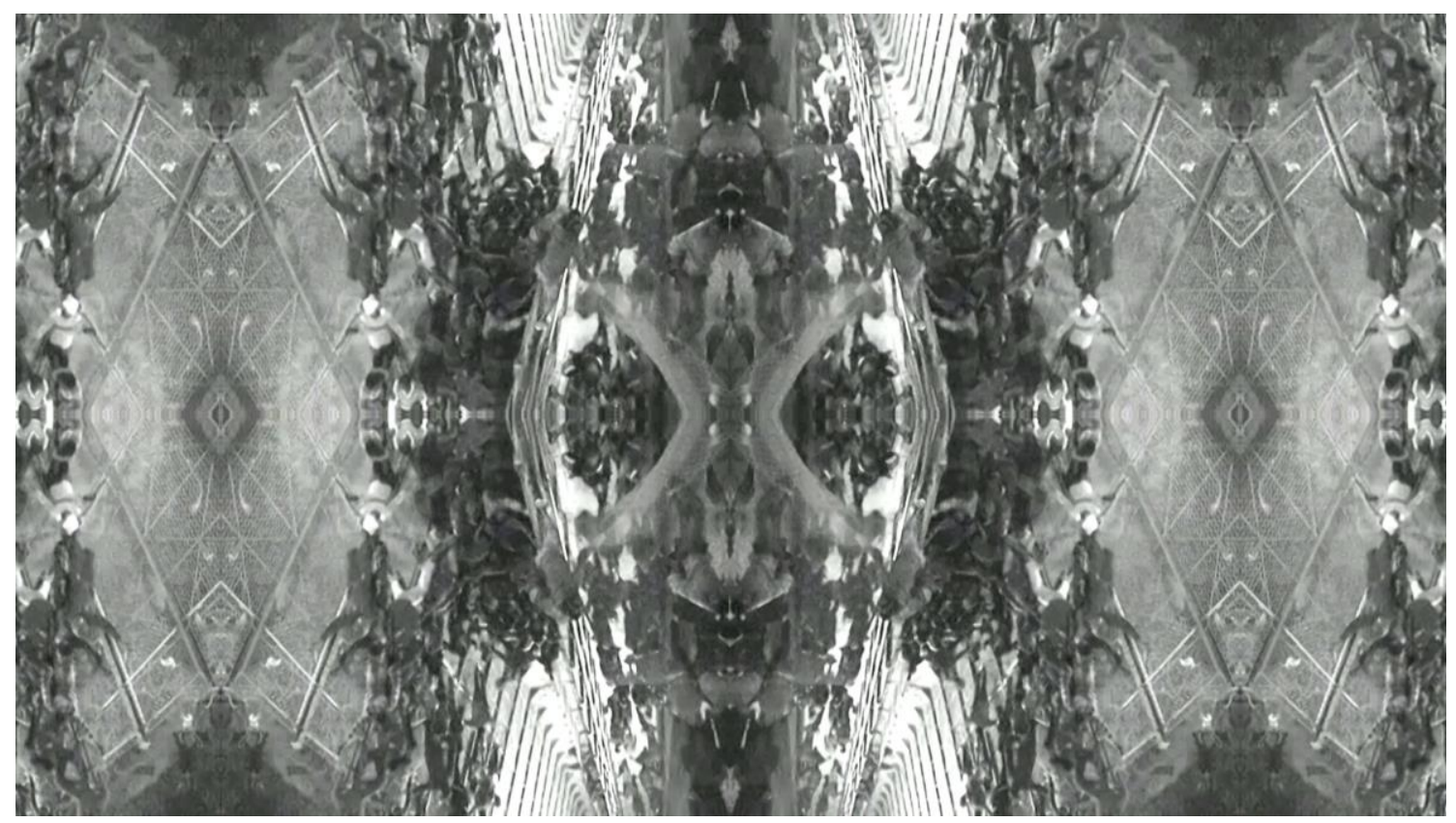

Figura 1. Fotograma de vídeo. “No Vanishing Point”, José A. Soriano. 2017. Fuente: (Dip. Granada, 2019, p. 59).

\section{Sistemas de representación}

Si las imágenes tienen la capacidad de modificar la percepción que los humanos tenemos de la realidad, el sistema de representación que empleemos para precisamente representar esta realidad a través de la creación de una imagen, debe tener un papel fundamental en esta conceptualización de la misma. Según Brea, existe un patrón o "episteme visual" que se ha repetido en la mayoría de imágenes artísticas y que es el culpable de que identifiquemos algunas imágenes como piezas de arte. Esta estructura a lo largo de la historia del arte ha tenido lugar a través de diferentes sistemas de representación, los cuales los artistas entendían como el ideal para representar sus propuestas. Así encontramos la perspectiva matemática como el que podría ser considerado el sistema hegemónico desde su conceptualización en el Renacimiento ${ }^{6}$. A pesar de ser considerado como un sistema científico y cerrado, los artistas lo han utilizado a su antojo, dando lugar a alteraciones extremas de sus fundamentos como resultó ser la anamorfosis (Baltrusaitis, 1978, p. 203) ${ }^{7}$; que era estudiada por jesuitas como Jean François Niceron o Salomon de Caus como representantes del pensamiento contemporáneo barroco acerca de la falsedad en la percepción y la trascendencia espiritual. La imagen resulta difícil de percibir verdaderamente, más que únicamente desde el punto de vista fijo, que en el Barroco quedaba directamente relacionado con la fe en Dios. Quizás la descontextualización espacial dada por dicho punto de vista, tomado de la perspectiva matemática, era interpretada

5 "Cultura Visual significa el final de la distinción entre imágenes artísticas y no artísticas, una disolución de la historia del arte en la historia de las imágenes. Esto quizás sea calificado como "democrático" o falacia de "lo nivelado"; [...]". En este caso Mitchell introduce el término falacia porque considera que existen problemas semióticos a la hora de distinguir entre imágenes artísticas y no artísticas, entre otras dualidades.

${ }^{6}$ Podríamos hacer mención a otras teorías que traten sistemas alternativos y variaciones de la misma, aunque eso merecería una mayor extensión del discurso.

${ }^{7}$ Este término entendido tal y como lo conocemos tuvo lugar en el año 1657 por el jesuita Gaspar Schott (Alemania, 1608- 1666). 
Soriano-Colchero, Jose-Antonio; López-Vílchez, Inmaculada.

La práctica artística como medio de representación de los modos de percibir la realidad espacial en el occidente contemporáneo. Un análisis teórico del proyecto plástico y visual No Vanishing Point ;).

IV Congreso INTERNACIONAL DE INVESTIGACIÓN EN ARTES VISUALES ANIAV 2019

IMAGEN [N] VISIBLE]

http://dx.doi.org/10.4995/ANIAV.2019.9223

como una ascensión divina. Sin embargo, es justamente la visión distorsionada de la anamorfosis la que interesa en el proyecto artístico que presentamos, ya que desde la distorsión se hace obvia la falsedad de la imagen y su capacidad para engañar al observador como bien hemos comentado en otros artículos (Soriano-Colchero, 2018).
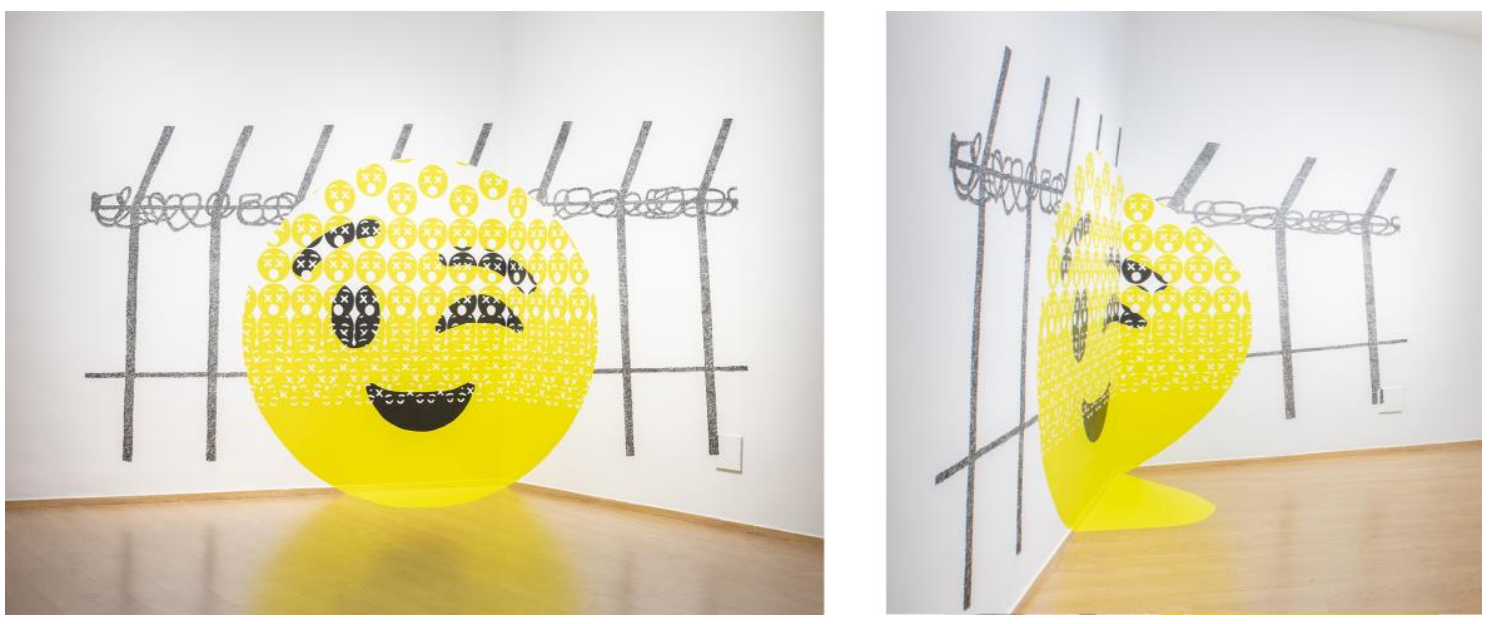

Figura 2. Pintura mural anamórfica. "No Vanishing Point ;) / The big face", José A. Soriano. 2019. Técnica mixta. Fuente: (Dip. Granada, 2019, p. 23.). (C) Limbo Agency, 2019.

\subsection{La representación en la imagen digital}

Acercándonos a nuestra contemporaneidad, la fotografía supuso una nueva revolución en cuanto a la representación de la realidad, que apareció como fruto de un largo proceso de investigación previo por científicos interesados en la óptica. Tras el proceso fotográfico del positivo - negativo por parte de Henry Fox Talbot (Reino Unido, 1800 - 1877), la imagen podría ser observada a partir de reproducciones de las mismas, en contextos totalmente diferentes a los originales.

\footnotetext{
"La técnica fotográfica permite operar sobre la realidad construyéndola de nuevo, ya que al reproducir, fragmentar, seleccionar o manipular, el medio físico puede ser reelaborado en una imagen: construir con él una representación. La fotografía será un medio capaz de desarrollar un sorprendente poder de transformación de la realidad". (Gómez Molina, 1999, p. 390).
}

Pero es la digitalización de la imagen la que da lugar a una verdadera transformación, por su capacidad de difusión y de multiplicación. En la imagen digital aparecen nuevas reglas capaces de generar mundos paralelos al real. Valga como ejemplo Google Street View, que a pesar de ofrecer la ilusión al observador de estar en un entorno digital tridimensional gracias a sus giros visuales de 360, su falta de fisicidad hace obvia la planicidad propia del medio digital.

\subsubsection{El emoticono}

Esta planicidad propia de la imagen digital la encontramos como antecedente en los iconos bizantinos o los posteriores góticos, representados sobre superficies doradas planas con el objetivo de descontextualizar la imagen divina y así pronunciar su sobrenaturalidad. Los iconos contemporáneos propios de las redes sociales, o emoticonos -del acrónimo inglés emoticon (emotion + icon)- (Real Academia Española, 2005) se presentan en la pantalla como imágenes planas sobre plano, pero al mismo tiempo pretenden funcionar como sustitutas de una emoción real, a modo de signos como diría F. J. Martel (2017): "[...] Ilamo signo a cualquier cosa cuya función sea la de remitir a cualquier otra cosa" (P. 71). Aunque podríamos discutir si realmente funcionan como signos, ya que presentan un sentimiento sintético y vacío de realidad que disfraza el mensaje de ingenuidad e inmadurez de tal manera que queda muy distante de lograr representar algo, convirtiéndose en símbolo: "[...] el símbolo es un signo que ha sido extraído de la secuencia mecanicista de causas y efectos para manifestarse de forma autónoma como pura imagen" (Op. cit. p. 73). Se han convertido en un lenguaje universal, instantáneo y a menudo irónico que es interpretado desde la superficialidad e impidiendo la verdadera percepción de una realidad, en crisis de valores y formada por individuos que tienden a la ausencia de capacidad crítica. "La peste social queda exorcizada por medio de las bufonerías" (Flórez, 2016, p. 122). Así podríamos confirmar que las imágenes propias del medio digital utilizan un sistema de representación que tienden a la teatralidad y el espectáculo; y que al igual que la mayoría de los anteriores requieren de un espectador espacialmente descontextualizado. 


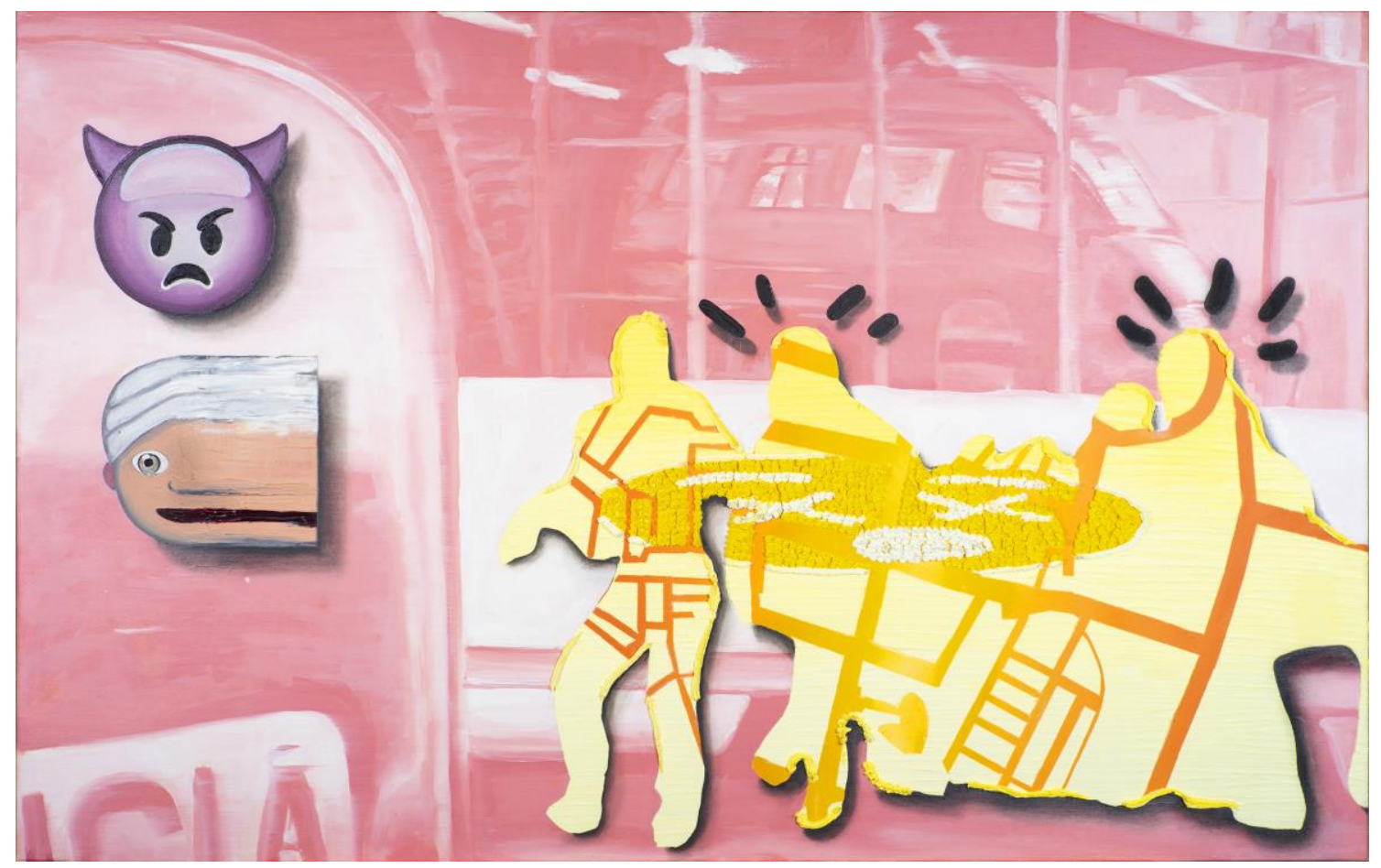

Figura 3. Pintura. "No Vanishing Point ;)". José A. Soriano. 2018. Óleo, spray y cera fría sobre lienzo. 116 x 73 cm. Fuente: (Dip. Granada, 2019, p. 19). (c) Limbo Agency, 2019.

\section{CONCLUSIONES}

Esta descontextualización común a las sociedades occidentales y occidentalizadas parte del uso creciente que hacemos de las nuevas tecnologías en nuestra vida diaria, invitándonos a compartir un espacio virtual común que resta importancia al real. El artificio hace que la estética tome más relevancia con respecto a los contenidos dando lugar a la acogida del Kitsch. Pero el Kitsch en el arte debe tener una connotación diferente a la que tiene fuera del mismo. A priori puede ser entendido como estética del sistema capitalista, motivo por el cual a Martel no le parece adecuado para ser aplicado al arte. Podríamos pensar que el Kitsch es ajeno al objetivo crítico y reivindicador del arte por su artificio y capacidad para ocultar: "Y el reino del artificio es el mayor peligro al que el arte se ha enfrentado jamás, aún mayor, a la larga, que la supresión directa de la libertad artística a los regímenes totalitarios" (Martel, 2017, p. 134). Sin embargo, de la misma manera que la anamorfosis es portadora de un mensaje revelador acerca de la facilidad de manipulación de las imágenes, el Kitsch en el arte se ofrece como estilo que trata sobre la estética de la imagen y su capacidad para ocultar aquello que no interesa ser revelado; apoyando al arte como generador de pensamiento crítico frente a la intersubjetividad inducida por los medios.

\section{FUENTES REFERENCIALES}

Baltrusaitis, J. (1978). Anamorfosi, o magia artificiale degli efetti meravigliosi (1a ed.). Milano: Adelphi Edizioni.

Brea, J. L. (2010). Las tres eras de la imagen: imagen-materia, film, e-imagen (1a. ed.). Móstoles (Madrid). Ediciones Akal, S. A.

Castro-Flórez, F. (2016). Estética a golpe de like. Post - comentarios intempestivos sobre la cultura actual [sin notas a pie de página] (1a ed.). Murcia: NewCastle Ediciones.

Diputación de Granada. (2019). José A. Soriano. No Vanishing Point ;): [Exposición], febrero - marzo 2019, Palacio de los Condes de Gabia de Granada (1a. ed.). Granada: Diputación de Granada. 
Soriano-Colchero, Jose-Antonio; López-Vílchez, Inmaculada.

La práctica artística como medio de representación de los modos de percibir la realidad espacial en el occidente contemporáneo. Un análisis teórico del proyecto plástico y visual No Vanishing Point ;).

IV Congreso INTERNACIONAL DE INVESTIGACIÓN EN ARTES VISUALES ANIAV 2019 IMAGEN [N] VISIBLE]

http://dx.doi.org/10.4995/ANIAV.2019.9223

Fontcuberta, J. (2016). La furia de las imágenes: Notas sobre la postfotografía (1a. ed.). Barcelona: Galaxia Gutenberg.

Gómez-Molina, J. J. (1999). Máquinas y herramientas del dibujo. Madrid: Cátedra.

Martel, J. F. (2017). Vindicación del arte en la era del artificio (1a ed.) Salamanca: Atalanta.

Mitchell, W. J. T. (2005). What do pictures want? : The lives and loves of the images (1a ed.). Chicago: University of Chicago press.

Mitchell, W..J. T. (2009). Teoría de la imagen: Ensayos sobre la representación visual y verbal (1a Ed.). Madrid: Akal / Estudios Visuales.

Querol, J. M. (2016). iFronteras! Estados, naciones e identidades (1a ed.). España: Díaz \& Pons Editores.

Real Academia Española. (2005). Diccionario panhispánico de dudas. Recuperado 27 febrero 2018 , de http://lema.rae.es/dpd/srv/search?key=emoticono

Soriano-Colchero, J. (2018). Arte, anamorfosis y percepción espacial: la realidad del observador. AusArt: Journal of Research in Art. 6(1), 249-259. https://doi.org/10.1387/ausart.19375 